\title{
P-0996 - Assessment of fetal biometric measures in prediction of gestational diabetes
}

Y. Ghanem. Departement of Internal Medicine, Alexandria University, Egypt.

\section{Assessment Of Fetal Biometric Measures In Prediction Of Gestational Diabetes}

\section{Background}

Gestational diabetes mellitus carries risk for both fetus and mother. Early detection and management of GDM has an important role to reduce its complications. Increased fetal biometric measures may play a role in predicting the occurrence of GDM.

\section{Aim}

The aim of the study is to is to correlate between the measurement of three potential markers, namely fetal fat layer (FFL), interventricular septum (IVS) and abdominal circumference (AC) percentile, and $75 \mathrm{gm} 2 \mathrm{hr}$ oral glucose tolerance test (OGTT) in pregnant women between 22 and 26 weeks gestation and the use of fetal biometric measures in prediction of gestational diabetes mellitus.

\section{Method}

The study includes 150 pregnant women between 22 and 26 weeks of gestations, all pregnant women were subjected to thorough history taking including present and past medical history, obstetric history and family history of diabetes mellitus.

Laboratory investigations included routine test as CBC, liver and renal function tests (to exclude any systemic disease), 75 gm $2 \mathrm{hr}$ oral glucose tolerance test and 2D Ultrasound assessment of FFL, IVS and AC.

\section{Results}

In this study, the principle finding was that fetal biometric measures (FFL, IVS and AC) are significantly increased with increasing blood glucose level either fasting $(\mathrm{P}=0.003,0.002$ and $<0.001$ respectively), $1 \mathrm{~h}(\mathrm{P}=0.003,0.004$ and $<0.001$ respectively) or $2 \mathrm{~h}$ post $75 \mathrm{gm}$ oral glucose $(\mathrm{P}<0.001$ for the three measures). There was significant difference in FFL, IVS thickness between diabetic and non diabetic pregnant women, $\mathrm{P}$ $=0.010$ and 0.016 respectively. On the other hand, the difference in abdominal circumference between diabetic and non diabetic pregnant women was non significant, $\mathrm{P}=0.162$.

\begin{tabular}{|c|c|c|c|c|c|c|c|c|c|c|}
\hline & & None GDM & GDM & $\stackrel{U}{4}$ & $=$ & 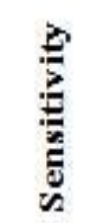 & 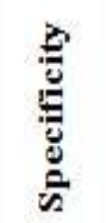 & $\overrightarrow{2}$ & $\overrightarrow{\mathrm{z}}$ & 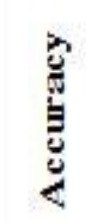 \\
\hline \multirow{2}{*}{ Fetal Fat Layer } & $\leq 3.7$ & 100 & 1 & \multirow{2}{*}{$0.815^{\circ}$} & \multirow{2}{*}{0.005} & \multirow{2}{*}{85.71} & \multirow{2}{*}{69.93} & \multirow{2}{*}{12.24} & \multirow{2}{*}{99.01} & \multirow{2}{*}{70.67} \\
\hline & $>3.7$ & 43 & 6 & & & & & & & \\
\hline \multirow{2}{*}{$\begin{array}{l}\text { Interventricular } \\
\text { Septum }\end{array}$} & $\leq 2.9$ & 92 & 0 & \multirow{2}{*}{0.772} & \multirow{2}{*}{0.015} & \multirow{2}{*}{100.0} & \multirow{2}{*}{63.34} & \multirow{2}{*}{12.07} & \multirow{2}{*}{100.0} & \multirow{2}{*}{66.0} \\
\hline & $>2.9$ & 51 & 7 & & & & & & & \\
\hline \multirow{2}{*}{$\begin{array}{l}\text { Abdominal } \\
\text { Circumference }\end{array}$} & $\leq 188$ & 56 & 0 & \multirow{2}{*}{0.657} & \multirow{2}{*}{0.162} & \multirow{2}{*}{100.0} & \multirow{2}{*}{39.16} & \multirow{2}{*}{7.45} & \multirow{2}{*}{100.0} & \multirow{2}{*}{42.0} \\
\hline & $>188$ & 87 & 7 & & & & & & & \\
\hline
\end{tabular}

Table: Sensitivity \& specificity for fetal biometric measures with GDM subjects

\section{Discussion}

In conclusion, our study demonstrated significant relation between the three measured fetal biometric measures (FFL, IVS and AC) and blood glucose level. 